This document is confidential and is proprietary to the American Chemical Society and its authors. Do not copy or disclose without written permission. If you have received this item in error, notify the sender and delete all copies.

\title{
Isothermal crystallization kinetics of palm oil as influenced by addition of a commercial phytosterol ester mixture
}

\begin{tabular}{|r|l|}
\hline Journal: & Journal of Agricultural and Food Chemistry \\
\hline Manuscript ID & jf-2017-05049n.R1 \\
\hline Manuscript Type: & Article \\
\hline Date Submitted by the Author: & n/a \\
\hline Complete List of Authors: & $\begin{array}{l}\text { Daels, Eva; KU Leuven, Microbial and molecular systems; Leuven Food } \\
\text { Science and Nutrition Research Centre (LFoRCe) } \\
\text { Goderis, Bart; Katholieke Universiteit Leuven Faculteit Wetenschappen, } \\
\text { Polymer Chemistry and Materials } \\
\text { Matton, Valerie; KU Leuven, Microbial and Molecular Systems; Leuven Food } \\
\text { Science and Nutrition Research Centre (LFoRC) } \\
\text { Foubert, Imogen ; KU Leuven, Microbial and Molecular Systems; Leuven } \\
\text { Food Science and Nutrition Centre (LFoRCe) }\end{array}$ \\
\hline & \\
\hline
\end{tabular}


1 Isothermal crystallization kinetics of palm oil as influenced by addition of a commercial phytosterol ester mixture

3 Eva Daels $^{\mathrm{a}}$, Bart Goderis ${ }^{\mathrm{b}}$, Valerie Matton ${ }^{\mathrm{a}}$ and Imogen Foubert*a

$4 \quad{ }^{a}$ Research Unit Food and Lipids, KU Leuven Kulak, Etienne Sabbelaan 53 box 7659, 8500 Kortrijk, 5 Belgium and Leuven Food Science and Nutrition Research Centre (LFoRCe), Kasteelpark Arenberg 20 6 box 2463, 3001 Leuven, Belgium.

$7 \quad{ }^{b}$ KU Leuven Polymer Chemistry and Materials, Celestijnenlaan 200f box 2404, 3001 Leuven, Belgium.

8 *Contact details: +32(0) 56246173 , imogen.foubert@kuleuven.be

9 Keywords: phytosterol esters, functional food, crystallization, X-ray diffraction

\section{Abstract}

In literature there is a good agreement on the health-promoting effects of phytosterols. However addition of phytosterol esters (PEs) to lipid (containing food products) may influence its crystallization behavior. This study investigated the crystallization kinetics of palm oil (PO) after addition of PEs in high concentrations $(\geq 10 \%)$. The isothermal crystallization of the PE-PO blends was analyzed at a temperature of $20^{\circ} \mathrm{C}$ and at a supercooling of $18.7^{\circ} \mathrm{C}$ using differential scanning calorimetry and timeresolved synchrotron X-ray diffraction. At increasing PE concentrations PO crystallization at an isothermal temperature of $20^{\circ} \mathrm{C}$ started later, was slower and less crystals were formed. Furthermore a delay in polymorphic transition from $\alpha$ to $\beta$ ' was observed. When the blends were isothermally crystallized at a supercooling of $18.7^{\circ} \mathrm{C}$ only two of these effects remained: the delay in polymorphic transition and the decrease in crystalline content.

\section{Introduction}

Palm oil (PO) is derived from the mesocarp of the fruit of the oil palm tree (Elaeis guineensis). It has surpassed soybean oil to be the most consumed vegetable oil in the world because of its unique 
24 physical properties ${ }^{1}$. It is very stable in the $\beta^{\prime}$ crystal form which is the most preferred polymorphic

25 form in food products like margarines and shortenings because $\beta$ ' crystals provide a smooth and glossy 26 texture ${ }^{1,2}$. Because PO is semi-solid at room temperature, it forms the ideal hard stock to be used in 27 trans free food products ${ }^{3}$. PO contains many different types of TAG, diacylglycerols, free fatty acids and other minor components and it exhibits different polymorphic forms. The polymorphism of a lipid refers to the packing arrangement of the molecules within the crystals. The $\alpha$ polymorphic form has the lowest thermodynamic stability but it has the ability to transform into the more stable $\beta^{\prime}$ or $\beta$ forms ${ }^{4}$. Polymorphism of PO during isothermal crystallization has been extensively studied by several authors ${ }^{3,5-8}$ who reported that the isothermal crystallization mechanism of PO depends on the degree of supercooling. At a high degree of supercooling, PO displays a two-step crystallization with the formation of $\alpha$ crystals in the first step, followed by a transformation into $\beta$ ' crystals and additional formation of $\beta$ ' crystals directly from the melt. At a lower degree of supercooling PO crystallizes directly into the $\beta$ ' polymorph without the prior formation of an $\alpha$ polymorph. The reported value of the cut-off temperature between both mechanisms varies between 22 and $25^{\circ} \mathrm{C}$ probably because of a difference in experimental conditions on the one hand and a difference in PO composition on the other hand $d^{3}$.

Phytosterols have recently gained much scientific and commercial interest due to the introduction of cholesterol-lowering foods enriched in plant sterols. Phytosterols contain over 250 different compounds including plant sterols and their hydrogenation products, plant stanols ${ }^{9}$. Since the chemical structure of phytosterols is very similar to that of cholesterol, an optimal intake of plant sterols and stanols decreases the intestinal cholesterol absorption and thereby reduces serum LDL cholesterol concentrations by $6-12 \%{ }^{10}$. Phytosterols are already present in the normal diet for example in vegetable oils, cereal grains and nuts but the levels are too low to provide significant cholesterol-lowering properties $^{11}$. The most efficient dietary tool to lower serum cholesterol levels are functional foods enriched with plant sterols. A meta-analysis on 124 studies showed that with an intake of phytosterols of 1.5-3 g/day a dose-dependent reduction in the blood levels of LDL-cholesterol of 7-12.5\% can be 
50

51

52

53

54

obtained $^{10}$. Among the currently available sterol-based foods, spreads are by far the most common food type, followed by dairy foods and drinks ${ }^{12}$. The concentration of phytosterol esters (PEs) that is applied in the fat phase in these products is in the range of 10 to $50 \%$ depending on the product type. Evidently, with only $10 \% \mathrm{PE}$ addition the chance of reaching the advised daily phytosterol intake remains rather low ${ }^{13}$. Food products with rather high PE loading therefore seem very relevant.

In literature there is a good agreement on the health-promoting effects of phytosterols, however addition of PEs to lipid (containing food products), in particular at high amounts, may influence its crystallization behavior and may thus lead to problems occurring during the production process or with the macroscopic properties of the end product. Fundamental research on this topic is very scarce. In a previous study we examined the effects of the addition of a commercial PE mixture on the nonisothermal crystallization behavior of PO and constructed morphology maps that show the different polymorphic forms as a function of temperature and PE concentration during cooling and heating ${ }^{14}$. It was shown that the PEs crystallized separately from PO and formed two different ordered structures, namely the higher-melting truly crystalline structure named $\mathrm{PE}_{\mathrm{x}}$ which was composed of stearic and palmitic acid esterified PEs and the lower-melting liquid crystalline structure $\mathrm{PE}_{\mathrm{y}}$ which mainly contained phytosteryl oleate.

These results enabled research on the impact of adding PEs to PO under industrially more relevant crystallization conditions. More specifically we investigated the influence of PE addition on the 'equilibrium' crystallization state of PO in order to evaluate whether PE addition gives desired properties to the end product ${ }^{15}$. It was found that PE addition has a major influence on each level of the crystalline structural hierarchy (primary crystallization, polymorphism, network formation and textural properties). Next to the effects related to the final 'equilibrium' state, it would be interesting to verify whether PE addition also influences the crystallization kinetics of PO. Diluting PO with PE is expected to delay or slow down the PO crystallization. The extent of this delay and the impact on the rate of polymorphic transitions is however, less predictable. To the best of our knowledge the effect of adding PEs on the isothermal PO crystallization kinetics has not been reported in literature before. More 
76

77

78

79

80

81

82

83

84

85

86

87

88

89

90

91

92

93

94

95

96

97

98

99

100

101

generally, the effect of addition of many other types of lipids like mono- and diglycerides on the crystallization kinetics of different edible oils and lipids has been studied, but mostly in low concentrations $(<10 \%)$ since these minor components can already influence the kinetics at a concentration $<0.1 \%{ }^{16}$.

Given that the concentration range of PEs in the fat phase of most of the existing cholesterol lowering fat rich food products is 10 to $50 \%$, and because of the relevance of higher concentrations, the objective of this study was to investigate the crystallization kinetics of PO after addition of PEs in high concentrations $(\geq 10 \%)$. Such information is required to assess the potential impact of adding high PE amounts in related food products under processing conditions. A commercially available mixture of PEs containing different types of phytosterols esterified to different types of fatty acids was added to PO in concentrations of $0,10,20,30$ and $40 \%$. The isothermal crystallization of the PE-PO blends was analyzed at a temperature of $20^{\circ} \mathrm{C}$ to examine the effect of PE addition on the two-step crystallization mechanism of PO. In a second set of experiments crystallization was studied at a constant supercooling of $18.7^{\circ} \mathrm{C}$ in order to eliminate (obvious) effects on the crystallization kinetics related to differences in degree of supercooling of the blends. Differential scanning calorimetry (DSC) was used to get a first view on the isothermal crystallization mechanism and to provide quantitative data on the kinetic behavior by applying the Foubert model. The crystallization mechanism and the polymorphic behavior was examined with time resolved synchrotron X-ray diffraction (XRD) analyses for selected measurements. Furthermore polarized light microscopy (PLM) was used to study the microstructure of the blends.

\section{Materials and methods}

\subsection{Materials}

PO and a commercial PE mixture were donated by Unilever (Vlaardingen, The Netherlands). As determined by solid phase extraction using the method described in Panpipat et al. (2013) ${ }^{17}$ the commercial PE mixture had a degree of esterification of $97.7 \pm 1.1 \%$. The sterol composition of the commercial PE mixture as measured by the method described in Ryckebosch, Bruneel, et al. (2012) ${ }^{18}$ is 
102

103

shown in Table 1. Table 2 depicts the fatty acid composition of PO and the commercial PE mixture as determined by the method described in Ryckebosch, Muylaert, \& Foubert (2012) ${ }^{19}$. Finally, Table 3 reports the triglyceride (TAG) composition of the PO which was analyzed in a high-performance liquid chromatograph (Waters, Belgium) coupled with a refractive index detector (Waters, Belgium). A NOVA-Pak C18 column ( $4 \mu \mathrm{m}, 150 \times 3.9 \mathrm{~mm}$; Waters, Belgium) was used at $30^{\circ} \mathrm{C}$. The mobile phase was acetonitrile-acetone (37.5:62.5, vol/vol). PO was solubilized in a chloroform/methanol mixture $(1: 1, \mathrm{vol} / \mathrm{vol})$ at a concentration of $20 \mathrm{mg} / \mathrm{ml}$ and samples of $20 \mu \mathrm{l}$ were injected in duplo.

\subsection{Blend preparation}

PEs were added to PO in concentrations of $10,20,30$ and $40 \%$ by weight. The samples were prepared after complete melting of the lipids at $80^{\circ} \mathrm{C}$ for 30 min under continuous stirring to obtain a homogeneous, clear mixture.

\subsection{Differential Scanning Calorimetry}

The DSC experiments were performed using a DSC Q2000 (TA Instruments, Brussels, Belgium) equipped with an autosampler. About $15 \mathrm{mg}$ of melted lipids was sealed into hermetic aluminum pans (TA Instruments, Brussels, Belgium). Three different types of DSC experiments were performed on the pure PO and the PE-PO blends: isothermal crystallization experiments, stop-and-return experiments and determination of the melting curve after reaching the 'equilibrium' state to determine $\mathrm{T}_{\text {offset. }}$ All measurements were carried out at least five times. For the isothermal crystallization experiments the following time-temperature program was used: equilibration at $80^{\circ} \mathrm{C}$ during $15 \mathrm{~min}$ to ensure complete melting and to erase the crystal memory, followed by cooling at $10^{\circ} \mathrm{C} / \mathrm{min}$ to the isothermal temperature $\left(20^{\circ} \mathrm{C}\right.$ or alternatively a degree of supercooling of $\left.18.7^{\circ} \mathrm{C}\right)$ and holding at that temperature until crystallization had finished. The Universal Analysis 2000 software version 4.5A (TA Instruments, New Castle, USA) was used to determine the peak maximum of the $\alpha$ peak $\left(\mathrm{t}_{\alpha \text { peak }}\right)$ which corresponds to the first peak in the isothermal crystallization curve. The start point and the end point of the $\beta$, crystallization, which is the second step in the two-step crystallization of PO, were determined using an objective calculation algorithm described by Foubert et al. $(2002)^{20}$. Next to the two peaks due to the $\alpha$ 
128

129

130

131

132

133

134

135

136

137

138

139

140

141

142

143

144

145

146

147

148

149

150

151

152

and $\beta$ ' crystallization of $\mathrm{PO}$ a third peak occurred in the isothermal crystallization curve of the $40 \% \mathrm{PE}$

blend at a supercooling of $18.7^{\circ} \mathrm{C}$ indicating PE crystallization. This peak was however not further analyzed. For indicative purposes the isothermal crystallization experiments at a temperature of $20^{\circ} \mathrm{C}$ were also performed on the pure PEs, but this DSC crystallization curve was also not further analyzed.

Stop-and-return experiments were performed as described in detail in Foubert et al. $(2008)^{21}$ for the quantitative analysis of the $\alpha$ crystallization, which is the first step in the two-step crystallization of PO.

In this technique the isothermal crystallization was interrupted after the $\alpha$ crystallization, followed by heating the sample at $20^{\circ} \mathrm{C} / \mathrm{min}$ to obtain the melting curve. The end point of the $\alpha$ crystallization was defined as the start point of the $\beta$ ' crystallization which had been determined with the calculation algorithm of Foubert et al. $(2002)^{20}$. The melting enthalpy of the $\alpha$ polymorph $\left(\Delta H_{\alpha}\right)$ was calculated by integration of the melting curve using a horizontal baseline with a fixed end point at $50^{\circ} \mathrm{C}$ and the starting point being the intersection of the melting curve with the horizontal baseline.

A last type of DSC experiment was designed to determine the offset temperature of melting $\left(\mathrm{T}_{\text {offset }}\right)$ of pure PO and the PE-PO blends. As described by Daels et al $(2017)^{15}$ a time-temperature profile of $48 \mathrm{~h}$ at $10^{\circ} \mathrm{C}$ was used to bring the samples in the 'equilibrium' (or kinetically stabilized) state. Then the samples were heated at $20^{\circ} \mathrm{C} / \mathrm{min}$ to $80^{\circ} \mathrm{C}$ to obtain the melting profile. $\mathrm{T}_{\text {offset }}$ of the peak in the melting curve was determined as the inflection point of the melting peak at the high temperature side of the peak, according to Timms $(2003)^{22}$. The degree of supercooling of the blends was calculated using this $\mathrm{T}_{\text {offset. }}$

\subsection{Time-resolved Synchrotron X-ray Diffraction}

Pure PO and PO with 20 and 40\% of PEs added were analyzed by time-resolved synchrotron X-ray diffraction experiments conducted at DUBBLE, the Dutch-Belgian beamline (BM26) at the European Synchrotron Radiation Facility (ESRF; Grenoble, France). Combined small-angle X-ray scattering (SAXS) and wide-angle X-ray diffraction (WAXD) patterns were recorded using a wavelength, $\lambda$, of $1.033 \AA$. The beamline was equipped with a two-dimensional Pilatus $1 \mathrm{M}$ detector to capture the SAXS 
153

154

155

156

157

158

159

160

161

162

163

164

165

signals and a Pilatus $300 \mathrm{~K}$ detector to gather the WAXD data. The scattering angles were calibrated with silver behenate and high-density polyethylene standards.

Approximately $15 \mathrm{mg}$ of melted lipids was sealed into hermetic aluminum pans (TA Instruments, Brussels, Belgium) and loaded onto a temperature-controlled sample stage (Linkam HFS 191, Surry, UK). The following time-temperature program was used: equilibration at $80^{\circ} \mathrm{C}$ during 15 min to ensure complete melting and to erase the crystal memory, followed by cooling at $10{ }^{\circ} \mathrm{C} / \mathrm{min}$ to the isothermal crystallization temperature which is at a degree of supercooling of $18.7^{\circ} \mathrm{C}$ and holding at that temperature until crystallization had finished. During the isothermal crystallization period the SAXS and WAXD patterns were captured simultaneously every $12 \mathrm{~s}$. Each time frame consisted of $11.985 \mathrm{~s}$ measuring time and $0.005 \mathrm{~s}$ data saving. The 2D SAXS and WAXD data were azimuthally averaged using the program Cone $\mathrm{X}^{23}$, normalized to the intensity of the incoming beam measured by a photodiode placed downstream from the sample and corrected for the empty holder scattering. The scattering angle $2 \theta$ ranged from $0.48<2 \theta<7.29^{\circ}$ for SAXS and $6.63<2 \theta<21.9^{\circ}$ for WAXD. A WAXD background correction was executed by taking the average of about ten data points at about $2 \theta$ $=21.9^{\circ}$ and subtracting this average from all data points. Thereafter, all patterns were normalized to their integral. Identification of the polymorphs was done on the basis of literature data ${ }^{3,6,8,14}$.

The WAXD data were also quantitatively analyzed to obtain the fractions of the different polymorphic forms as a function of the isothermal time and this is further explained on the basis of Figure 1. For pure PO and PO with 20\% PEs the same method was applied to extract the fractions of the $\alpha$ and $\beta$, polymorphs from WAXD. First a reference pattern of the amorphous phase ('amorphous reference'; Fig. 1A) was made by averaging the last ten WAXD patterns during the cooling because no crystallization occurred in that stage. The reference pattern of the $\alpha$ polymorph (' $\alpha$ reference') as shown in Figure 1A was obtained by first selecting the WAXD pattern where the intensity of the $\alpha$ peak was maximal and no peaks of other polymorphic forms were present (named ' $\alpha$ frame' in Figure 1A). The peak maximum of the $\alpha$ peak in the ' $\alpha$ frame' was located at $2 \theta=13.2^{\circ}(\mathrm{d}=4.22 \AA)$. Then the 'amorphous reference' was scaled to fit in the ' $\alpha$ frame' (named 'scaled amorphous reference' in Figure 
179

180

181

182

183

184

185

186

187

188

189

190

191

192

193

194

195

196

197

198

199

200

201

202

203

204

$1 \mathrm{~A}$, scaling factor $=0.91$ ) and this 'scaled amorphous reference' was subtracted from the ' $\alpha$ frame' to acquire the ' $\alpha$ reference'. As a final step the intensities to the left and right side of the peak in the ' $\alpha$ reference' were set to 0 , resulting in the 'cleaned $\alpha$ reference'. The reference pattern of the $\beta$ ' polymorph was made analogously as shown in Figure 1B. The ' $\beta$ ' frame' contained three peaks at $2 \theta=$ $13.4^{\circ}(\mathrm{d}=4.41 \AA), 2 \theta=13.9^{\circ}(\mathrm{d}=4.27 \AA)$ and $2 \theta=15.0^{\circ}(\mathrm{d}=3.95 \AA)$. As can be seen on Figure $1 \mathrm{~B}$ the scaling factor to fit the 'amorphous reference' in the ' $\beta$ ' frame' was smaller than for the ' $\alpha$ frame' and equaled 0.85. Subsequently all WAXD patterns were fit with a linear combination of the 'amorphous reference', the 'cleaned $\alpha$ reference' and the 'cleaned $\beta$ ' reference' with the intensities of the amorphous phase and the different polymorphic forms as unknown parameters. The area below each of the constituting curves corresponds to the phase specific mass fractions. Via the Excel Solver the sum of the squared residuals of this fit was minimized. For each pattern the sum of the fractions equaled 1.

For the PE-PO blend with $40 \%$ PEs the method to extract the fractions of the different polymorphic forms differed a little because only in these crystallization conditions and at this PE concentration the PEs also crystallized separately from PO, more specifically in the form of $\mathrm{PE}_{\mathrm{x}}$. The formation of the $\mathrm{PE}_{\mathrm{x}}$ crystals started after the $\alpha$ crystallization and before the polymorphic transition from $\alpha$ to $\beta$, crystals. Consequently there were no WAXD patterns in which only the $\mathrm{PE}_{\mathrm{x}}$ peaks occurred. Therefore to make the ' $\mathrm{PE}_{\mathrm{x}}$ frame' for the $\mathrm{PE}_{\mathrm{x}}$ reference (see Figure 1C), a WAXD pattern of pure PEs crystallized in the $\mathrm{PE}_{\mathrm{x}}$ form at $27^{\circ} \mathrm{C}$ was used since this temperature is higher than the melting temperature of $\mathrm{PE}_{\mathrm{y}}$, but lower than the melting temperature of $\mathrm{PE}_{\mathrm{x}}{ }^{14}$. The ' $\mathrm{PE}_{\mathrm{x}}$ frame' contained nine peaks: a weak peak at $2 \theta=7.81^{\circ}(\mathrm{d}=7.58 \AA)$, two strong sharp peaks at $2 \theta=9.54^{\circ}(\mathrm{d}=6.21 \AA)$ and $2 \theta=9.86^{\circ}(\mathrm{d}=6.02 \AA)$, again three weak peaks at $2 \theta=10.2^{\circ}(\mathrm{d}=5.81 \AA), 2 \theta=11.7^{\circ}(\mathrm{d}=5.08 \AA)$ and $2 \theta=12.4^{\circ}(\mathrm{d}=4.78 \AA)$, a strong double peak at $2 \theta=13.9^{\circ}(\mathrm{d}=4.27 \AA)$ and $2 \theta=14.1^{\circ}(\mathrm{d}=4.22 \AA)$ and one stronger peak at $2 \theta=15.2^{\circ}(\mathrm{d}=3.91 \AA)$. The scaling factor of the 'amorphous reference' was 0.90 in this case. Furthermore because of overlapping peaks in the WAXD patterns, the fits of most of the WAXD patterns of PO with 40\% PEs did not lead to unique solutions when more than one 
205 206 207 208 209 210

polymorphic form had crystallized. Therefore determination of the fractions of the different polymorphic forms was done differently for this sample. First the $\alpha$ fraction at an isothermal time of 10 min was determined via the WAXD data using the above described method since at that time no peaks of other polymorphic forms occurred. Then the $\alpha$ fraction as a function of the isothermal time was calculated from the integral of the $\alpha$ peak in the SAXS region between $2 \theta=3.74$ and $2 \theta=3.84$ and scaling of this (time dependent) integral to the WAXD based $\alpha$ fraction at 10 min. Subsequently all WAXD patterns were fitted again with the $\alpha$ phase fraction fixed to the scaled SAXS based value and with the fractions of the amorphous phase, the $\beta^{\prime}$ and $\mathrm{PE}_{\mathrm{x}}$ crystal form fractions left as adjustable parameters.

\subsection{Polarized light microscopy}

Using a polarized light microscope Olympus BX51 (Olympus Optical Co. Ltd., Tokyo, Japan) the microstructure of the samples was studied. A drop of melted sample was transferred onto a pre-heated and covered with a thin covering slide. Using a temperature-controlled Linkam PE120 stage (Linkam Scientific Instruments, Surrey, UK) the samples were heated at $80^{\circ} \mathrm{C}$ during 15 min to ensure complete melting and to erase the crystal memory, followed by cooling at $10^{\circ} \mathrm{C} / \mathrm{min}$ to the isothermal temperature at a degree of supercooling of $18.7^{\circ} \mathrm{C}$ and holding at that temperature until crystallization had finished. Images of the microstructures were captured with a digital camera Infinity 2 (Lumenera corporation, Ontario, Canada) and the Infinity capture software (Lumenera Corporation, Ottawa, Canada) every minute during the isothermal crystallization.

\subsection{Statistical analysis}

The obtained mean values of the crystallization parameters were statistically analyzed by one-way ANOVA with SigmaPlot version 11.0 (Systat Software, Drunen, The Netherlands). Furthermore with the same software Tukey tests were applied to determine significant differences between the mean values at a significance level of 0.05 .

\section{Results and discussion}

4.1. Isothermal crystallization at $20^{\circ} \mathrm{C}$ 
231

232

233

234

235

236

237

238

239

240

241

242

243

244

245

246

247

248

249

250

251

252

253

254

255

256

\subsubsection{Differential scanning calorimetry: qualitative analysis}

For each PE concentration $(0,10,20,30,40$ and 100\%) Figure 2A shows an overlay of one representative DSC isothermal crystallization curve at $20^{\circ} \mathrm{C}$. The isothermal crystallization curve of the pure PO showed two peaks which according to the WAXD data discussed below (see section 4.2.3) correspond to the crystallization of PO in the $\alpha$ polymorph (indicated as Peak I) and the subsequent polymorphic transition to the $\beta$ ' form followed by additional crystallization of $\beta$ ' crystals directly from the melt (indicated as Peak II). Many other studies reported this two-step crystallization mechanism when PO was isothermally crystallized at $20^{\circ} \mathrm{C}^{3,5-8}$. Peak I started immediately after cooling and was therefore not fully separated from the cooling segment in the DSC curve. However, Peak I was fully separated from Peak II. The isothermal crystallization curve of the pure PEs consisted of one single crystallization peak that also started immediately after cooling. Based on the melting temperatures of $\mathrm{PE}_{\mathrm{x}}\left(48.9^{\circ} \mathrm{C}\right)$ and $\mathrm{PE}_{\mathrm{y}}\left(19.9^{\circ} \mathrm{C}\right)$ as reported by Daels et al. $(2017)^{14}$ it is conceivable that this peak is dominated by the crystallization of $\mathrm{PE}_{\mathrm{x}}$. The DSC curve of the pure PEs is only shown for indicative purposes and, in contrast to the other curves, was not quantitatively analyzed. The isothermal crystallization curves of the PE-PO blends showed the same two peaks (Peak I and Peak II) as the curve of the pure PO, although shifted to higher crystallization times with increasing PE concentration. No peaks due to $\mathrm{PE}$ crystallization could be distinguished, although $\mathrm{PE}_{\mathrm{x}}$ crystallization might be hidden below the PO crystallization events for the blend containing 40\% PE. Indeed, in the quantitative DSC analysis an unexpected increase of the PO $\beta$ ' share was detected (see section 4.1.2), which might be due to non-legitimately allocated exothermic heat from the $\mathrm{PE}_{\mathrm{x}}$ crystallization. Relying on the morphology maps of PO/PE blends reported by Daels et al. (2017) ${ }^{14} \mathrm{PE}$ is expected to be at least partially in the $\mathrm{PE}_{\mathrm{x}}$ crystalline state in the blends of $\mathrm{PO}$ with $10-40 \%$ PEs at $20^{\circ} \mathrm{C}$. However, the same study reported that a large degree of supercooling is required for $\mathrm{PE}_{\mathrm{x}}$ to crystallize, which might translate into a large induction time for isothermal crystallization at $20^{\circ} \mathrm{C}$. This induction time seems to be longer than the isothermal crystallization time in the present study, except apparently for the sample with $40 \% \mathrm{PE}$ (see section 4.1.2). Just as in the isothermal crystallization curve of pure PO, Peak I and 
257 Peak II were fully separated in time, irrespective of the PE concentration. For all samples, except for 258 the 10\% PEs sample, Peak I was also fully separated from the cooling run (Figure 2B). When looking 259 at the isothermal crystallization curves of the PE-PO blends it can readily be observed that with an 260 increasing PE concentration Peak I and Peak II shifted to longer crystallization times, broadened and 261 became less intense. The lower intensity (i.e. the lower area covered by these peaks) obviously relates 262 to the lower amount of PO present in these blends. However, areas should be calculated quantitatively 263 to determine whether the reduced area simply follows the PO content or whether additional reducing effects are in place (see section 4.1.2 below). For Peak I, the shift and broadening effect can more 265 clearly be seen in Figure 2B.

4.1.2. Differential scanning calorimetry: quantitative analysis

267

268

269

270

271

272

273

274

275

276

277

278

279

280

281
Because the isothermal crystallization curves of pure PO and the PE-PO blends showed the same peaks (Peak I and Peak II), they were quantitatively analyzed in the same way. Since Peak I was not fully separated from the cooling segment in the isothermal crystallization curves of pure PO and some of the PE-PO blends it could not be integrated and analyzed in terms of a crystallization model. Therefore Peak I was quantitatively analyzed by determining the time at its peak maximum in the isothermal crystallization curve $\left(t_{\alpha}\right)$ and the melting enthalpy $\left(\Delta H_{\alpha}\right)$ obtained by integration of the endothermic melting peak obtained during heating in the stop-and-return experiments in which the isothermal crystallization was interrupted after the $\alpha$ crystallization. Both parameters are shown in Table 4. It was observed that $t_{\alpha}$ increased strongly as a function of the PE concentration (significant from 20\% PE) which indicates the $\alpha$ crystallization was delayed upon PE addition. After addition of $10 \%$ PEs to PO $t_{\alpha}$ was already doubled and when adding $40 \%$ PEs $t_{\alpha}$ increased even more than 20 times. $\Delta H_{\alpha}$ strongly decreased with increasing PE concentration showing that less $\alpha$ crystals were formed when adding an increasing amount of PE. For each PE concentration the decrease in $\Delta H_{\alpha}$ was much larger than expected from the reduced PO amount by adding PE. For example when $40 \%$ PEs were added $\Delta H_{\alpha}$ of PO became almost 10 times smaller. 
The $\boldsymbol{\beta}$ ' crystallization was analyzed using a well-established model to describe fat crystallization kinetics that was introduced by Foubert et al. $(2002)^{24}$ and which obeys the following algebraic equation:

$$
f(t)=a *\left[1-\left(1+\left(0.99^{1-n}-1\right) * e^{(n-1) * K *\left(t-t_{\text {ind }}\right)}\right)\right]^{\frac{1}{1-n}}
$$

When using DSC to follow the crystallization kinetics $f$ is the released crystallization heat $[\mathrm{J} / \mathrm{g}]$ at time $t[\mathrm{~h}]$ and increases with time in a sigmoidal way. $a$ is the value for $f$ as $t$ approaches infinity $[\mathrm{J} / \mathrm{g}$ ] which reflects the maximal amount of crystallization and $K$ is the crystallization rate constant $\left[\mathrm{h}^{-1}\right] . t_{\text {ind }}$ [h] is defined as the time needed to reach $1 \%$ of the $a$ value. It is a measure for the so-called induction time. $n$ is the reaction order (dimensionless) and is related to the degree of curve asymmetry. A value of 2 for $n$ means the sigmoidal curve is perfectly symmetric ${ }^{24}$. This model was fitted to the cumulative heat flow curve during the $\beta$ ' crystallization as a function of time. Because the parameters $n$ and $K$ are correlated, $n$ was fixed at 5.2, which was the mean value of $n$ of all measurements after the first fit and the fitting was subsequently redone with $n$ fixed at 5.2. A value of $n$ larger than 2 indicates that the beginning of the crystallization process is faster than the end ${ }^{24}$. Table 4 gives the parameters resulting from the Foubert model for the different blends. At higher PE fractions, $a$ clearly decreased (significant from $10 \%$ PE) indicating that less $\beta$ ' crystals were formed. When adding $30 \%$ PEs the decrease in $a$ was larger than the proportional amount of PE added. However, when adding 40\% PEs $a$ significantly increased relative to the value for the $30 \%$ PE blend. This was probably due to crystallization of PEs in the $40 \%$ PE blend as explained above in section 4.1.1. The $K$ value of the blends decreased up to $70 \%$ upon increasing the PE concentration, indicating a progressively slowing down $\beta$ ' crystallization. In case of the blend with $40 \%$ PEs a small (not significant) increase of $K$ relative to the value obtained for the $30 \%$ PE blend was observed which could also be due to PE crystallization in the $40 \%$ PE blend. Concerning $t_{\text {ind }}$ a strong increase was noticed with increasing PE concentration for all the PE-PO blends demonstrating that the start of the $\beta$ ' crystallization was delayed. In the blend with $40 \%$ PEs $t_{\text {ind }}$ was the highest being four times larger than $t_{\text {ind }}$ of pure PO. This makes sense since in this two-step crystallization, $\beta$ ' crystals are formed by polymorphic transition of $\alpha$ crystals of which the 
crystallization also started later upon PE addition. To verify whether the polymorphic transition itself was also effectively delayed, the polymorphic transition time from $\alpha$ to $\beta^{\prime}\left(t_{\text {transition }}\right)$ was calculated as the difference between $t_{\text {ind }}$ and $t_{\alpha}$ and the values are also represented in Table 4 . Clearly $t_{\text {transition }}$ increased with an increasing PE concentration (significant from 20\% PE) indicating $\beta$ ' crystallization started later not only due to the delayed $\alpha$ crystallization but also because of an increasingly delayed polymorphic transition. After adding $40 \%$ PEs $t_{\text {transition }}$ more than doubled compared to the value of pure PO. Furthermore also the total melting enthalpy after the isothermal crystallization $\left(\Delta H_{\text {tot }}\right)$ was calculated as the sum of $\Delta H_{\alpha}$ and $a$ and is also represented in Table 4. As could be expected from the decreasing trends in $\Delta H_{\alpha}$ and $a$ also $\Delta H_{t o t}$ decreased with an increasing PE concentration (significant from $10 \% \mathrm{PE})$. After adding $30 \%$ or more PEs $\Delta H_{\text {tot }}$ of PO was more than halved.

$\mathrm{T}_{\text {offset }}$ for each of the PE-PO blends was determined from the melting curves of the blends after reaching the 'equilibrium' state and are shown in Table 5. As $\mathrm{T}_{\text {offset }}$ of the PE-PO blends decreased with increasing PE concentration, the degree of supercooling during the isothermal measurements at $20^{\circ} \mathrm{C}$ also decreased with increasing PE concentration. Therefore the observed effects as a result of PE addition during isothermal crystallization at $20^{\circ} \mathrm{C}$ could have been caused by the difference in supercooling rather than being provoked by differences in PE concentration.

\subsection{Isothermal crystallization at a constant degree of supercooling of $18.7^{\circ} \mathrm{C}$}

In order to eliminate the difference in degree of supercooling of the blends, isothermal crystallization was analyzed at a constant supercooling of $18.7^{\circ} \mathrm{C}$. The isothermal temperature used for each blend was calculated based on $\mathrm{T}_{\text {offset }}$ and is shown in Table 5. The DSC data were used to get a first view on the isothermal crystallization mechanism and to provide quantitative data on the kinetic behavior by applying the Foubert model. This time also synchrotron XRD analyses were performed to examine the polymorphic behavior.

\subsubsection{Differential scanning calorimetry: qualitative analysis}

Figure 3A shows an overlay of representative isothermal crystallization curves of pure PO and PO with addition of different concentrations of PEs at a supercooling of $18.7^{\circ} \mathrm{C}$. The curve of pure PO during 
334 isothermal crystallization at $20^{\circ} \mathrm{C}$ has already been discussed in section 4.1.1. The isothermal 335 crystallization curves of the PE-PO blends with 10 to $30 \%$ PEs showed the same two peaks (Peak I and 336 Peak II) as the curve of pure PO and no other peaks (due to PE crystallization) could be visually 337 distinguished. For the blend with 20\% PEs it was later confirmed by XRD that PEs did not crystallize 338 during the isothermal crystallization at a supercooling of $18.7^{\circ} \mathrm{C}$ (see section 4.2 .3 ). The isothermal 339 crystallization curve of the blend with 40\% PEs showed one extra peak between Peak I and Peak II 340 which corresponded to the crystallization of PEs (later confirmed by XRD, see section 4.2.3). From 341 Figure 3A and more clearly from the detailed picture of Peak I in Figure 3B it is clear that Peak I was 342 sharp and started immediately after cooling in the isothermal crystallization curves of each of the PE343 PO blends. The intensity of Peak I became lower as a function of the PE concentration but there was no 344 noticeable effect of the PE concentration on the width of Peak I. Concerning Peak II the effects of PE 345 addition were clearer than for Peak I. With an increasing PE concentration Peak II became broader, was 346 shifted to later times and its intensity became lower.

347 4.2.2. Differential scanning calorimetry: quantitative analysis

348 Since the isothermal crystallization curves at a supercooling of $18.7^{\circ} \mathrm{C}$ of the PE-PO blends with 10 to $34930 \%$ PEs showed the same peaks (Peak I and Peak II) as the isothermal crystallization curve of pure PO 350 at $20^{\circ} \mathrm{C}$, their quantitative analysis was performed similarly. For the blend with $40 \%$ PEs, Peak I was 351 not fully separated from the PE crystallization peak and therefore no stop-and-return analysis could be 352 done on this sample and $\Delta \mathrm{H}_{\alpha}$ could not be determined. For the same blend Peak II was fully separated from the crystallization peak of the PEs and was therefore quantitatively analyzed in the same way as 354 Peak II of pure PO during isothermal crystallization at $20^{\circ} \mathrm{C}$.

355 The analyzed parameters for the $\boldsymbol{\alpha}$ crystallization $\left(t_{\alpha}\right.$ and $\Delta H_{\alpha}$ ) of the pure PO and the PE-PO blends 356 during isothermal crystallization at a supercooling of $18.7^{\circ} \mathrm{C}$ are reported in Table 6 . It can be seen that 357 the $\alpha$ crystallization of PO only started later once $40 \%$ PEs was added $\left(t_{\alpha}\right.$ increased). At lower PE 358 concentrations, no difference was observed with respect to the value of pure PO. The increase of $t_{\alpha}$ 359 was ten times less compared to when crystallization was executed at $20^{\circ} \mathrm{C}$ for the sample with $40 \%$ 
PEs. The observation that the $\alpha$ crystallization of the PE-PO blends during isothermal crystallization at $20^{\circ} \mathrm{C}$ was strongly delayed as a function of the PE concentration was therefore caused by the difference 362 in the degree of supercooling of the PE-PO blends, since this delay is nearly absent when the 363 isothermal temperature is corrected for this difference in the degree of supercooling. Furthermore, only 364 when at least $20 \%$ PEs were added $\Delta H_{\alpha}$ reduced significantly, indicating that besides a less outspoken 365 increase of $t_{\alpha}$ with increasing PE concentration, also the decrease of $\Delta H_{\alpha}$ is less pronounced at 366 constant degree of supercooling.

367 Table 6 also gives the parameters of the Foubert model resulting from the fit of the $\boldsymbol{\beta}$ ' peak during 368 crystallization at a supercooling of $18.7^{\circ} \mathrm{C}$. Less $\beta$ ' crystals were formed with an increasing PE 369 concentration ( $a$ decreased, significant from 10\% PE). Within experimental error the decrease in $a$ was 370 proportional to the PO amount, except for the sample with $40 \%$ PE for which the $a$ value was significantly lower than expected from proportionality. It cannot be excluded that part of the $\beta$ ' signal 372 was to be found in the preceding $\mathrm{PE}_{\mathrm{x}}$ crystallization exotherm. The XRD data (see further below) 373 demonstrate that these crystallization events are in fact not well separated in time. Furthermore, 374 according to the XRD data discussed further below it seems that the $\beta$ ' crystallization in the $40 \% \mathrm{PE}$ 375 sample slowly continues over a large time interval by which definition of the DSC integration base line 376 is rather uncertain. However, it will be demonstrated when discussing the XRD data that indeed the 377 ultimate $\beta$ ' crystalline content is somewhat lower than what can be expected from proportionality. At a 378 concentration exceeding $10 \% \mathrm{PE}$, the $\beta$ ' crystallization was also significantly slower compared to in 379 pure PO as a function of the PE addition ( $K$ decreased). Just as seen in the results for the isothermal 380 crystallization at $20^{\circ} \mathrm{C}$ in this case addition of $40 \%$ PEs did not lead to an increase of $K$ relative to the 381 value obtained for the $30 \%$ PE blend. Furthermore $\beta$ ' crystallization started later with an increasing PE 382 concentration as $t_{\text {ind }}$ increased significantly for all studied concentrations. In the $40 \%$ PE blend $t_{\text {ind }}$ 383 was the highest, being almost three times the value of $t_{\text {ind }}$ of pure PO. The increase of $t_{\text {ind }}$ upon PE 384 addition was smaller compared to that of the isothermal crystallization at $20^{\circ} \mathrm{C}$ which could be 
expected since also the increase of $t_{\alpha}$ was smaller for the PE-PO blends crystallized at a constant

386

387

388

389

390

391

392

393

394

395

396

397

398

399

400

401

402

403

404

405

406

407

408

409

410 supercooling of $18.7^{\circ} \mathrm{C}$.

Next to the parameters of the Foubert model, also $t_{\text {transition }}$ and $\Delta H_{t o t}$ of the PE-PO blends crystallized isothermally at a constant supercooling were analyzed. The polymorphic transition started later with an increasing PE addition ( $t_{\text {transition }}$ increased, significant from $10 \% \mathrm{PE}$ ). The change in $t_{\text {transition }}$ is almost equal to that of $t_{\text {ind }}$ indicating the delayed $\beta$ ' crystallization is not caused by a delay in $\alpha$ crystallization but is due to a delay of polymorphic transition from $\alpha$ to $\beta$ ' when PEs are added. Finally, $\Delta H_{\text {tot }}$ decreased significantly compared to pure PO when adding at least $20 \%$ PE, but there was no further decrease that exceeded the error estimate if more PEs were added. However, due to the rather large errors involved, the gradual PO dilution and the potential interference of PE crystallization at high $\mathrm{PE}$ concentration we refrain from drawing conclusions on potential PE crystallinity differences.

From the DSC analyses it can be concluded that the main effect related to adding PEs that remains after correcting the isothermal temperature of the PE-PO blends for the difference in the degree of supercooling is the delay of polymorphic transition (increase in $t_{\text {transition }}$ ). The fact that this transition occurs at temperatures below the melting temperature of the metastable $\alpha$ form suggests that this is a solid-solid transition rather than a melt-mediated transformation. The addition of PEs to PO in high concentrations (10-40\%) probably hinders the solid-state polymorphic transition because the $\alpha$ crystals are physically more isolated from each other. This physical separation requires multiple, nucleation events to trigger the conversion at each separated location. This leads to a globally increased transformation time. A single nucleation event can trigger the conversion over a larger volume when $\alpha$ crystals are well connected, as seems to be the case for pure PO. This hypothesis was later confirmed with PLM (see section 4.4). This effect is probably enhanced by Ostwald ripening, a melt-mediated process whereby the critical size for a stable crystal increases, causing the smaller crystals to dissolve and leading to less and bigger crystals ${ }^{25}$. Due to Ostwald ripening the isolation of the PO crystals is therefore even more pronounced. 


\subsection{X-ray diffraction}

412 The different polymorphic forms were unambiguously identified by comparing the SAXS and WAXD 413 patterns that were simultaneously recorded during the isothermal crystallization of pure PO and PO 414 with 20 and $40 \%$ PEs at a supercooling of $18.7^{\circ} \mathrm{C}$. The mass fractions of the different polymorphs were quantitatively analyzed based on the WAXD patterns. Figure 4 shows the SAXS diffraction patterns of pure PO recorded at different moments during the isothermal crystallization and Figure 5A represents the mass fractions of $\alpha$ and $\beta^{\prime}$ as function of the isothermal time. Conform the literature the isothermal crystallization of PO at $20^{\circ} \mathrm{C}$ occurred in two steps $\mathrm{s}^{3,5,6,8}$. Immediately after cooling, one strong first order peak at $2 \theta=1.27^{\circ}(\mathrm{d}=46.7 \AA)$ and one small third order peak at $2 \theta=3.48^{\circ}(\mathrm{d}=15.4 \AA)$ appeared in the SAXS patterns accompanied by one peak at $2 \theta=13.2^{\circ}(\mathrm{d}=4.22 \AA)$ in the WAXD patterns. These spacings are characteristic of the $\alpha$ polymorph in a 2 L-stacking. The $\alpha$ fraction reached a maximum of about 7\% (Fig. 5A). As deduced from the SAXS and WAXD data, the polymorphic transition to $\beta$ ' started after $7 \mathrm{~min}$. From that moment, one strong first order peak at $2 \theta=1.38^{\circ}(\mathrm{d}=$ $42.9 \AA)$ and a small third order peak at $2 \theta=4.18^{\circ}(\mathrm{d}=14.1 \AA)$ emerged in the SAXS patterns while the other peaks that were already present started to vanish. From the same moment onwards three peaks could be observed in WAXD at $2 \theta=13.4^{\circ}(\mathrm{d}=4.41 \AA), 2 \theta=13.9^{\circ}(\mathrm{d}=4.27 \AA)$ and $2 \theta=15.0^{\circ}(\mathrm{d}=$ $3.95 \AA$ ). An isosbestic point occurred in the SAXS patterns between 9 and 14 min since all the patterns of these frames passed through one single point (Fig. 4B). The isosbestic point indicates that the total crystal volume is constant during the polymorphic transition ${ }^{8}$. After 14 min approximately all $\alpha$ crystals were transformed to $\beta$ ' and extra $\beta$ ' crystals were formed directly from the melt. At the end of the 431 isothermal time the mass fraction of $\beta^{\prime}$ crystals was circa 15\% (Fig. 5A).

432 The SAXS and WAXD patterns of PO with 20\% PEs were very similar to those of pure PO since only 433 the typical PO peaks were observed and thus the PEs did not crystallize in this blend (detailed results 434 not shown). Just as for the pure PO, immediately after cooling $\alpha$ peaks appeared in the SAXS and 435 WAXD patterns. Figure 5B shows that the $\alpha$ fraction reached a maximum value of about $7 \%$. It was 
437 SAXS patterns an isosbestic point was observed from 12 to $24 \mathrm{~min}$ after which extra $\beta$ ' crystals were

438 formed directly from the melt. The fraction $\beta^{\prime}$ at the end of the isothermal time was approximately $439 \quad 13.5 \%$ (Figure 5B).

440 The isothermal crystallization at $18.7^{\circ} \mathrm{C}$ supercooling of PO with $40 \%$ PEs was different from that of 441 pure PO and PO with 20\% PEs since the PEs crystallized in this blend. Figure 6 shows the SAXS 442 patterns of PO with $40 \%$ PEs recorded at different moments in time during the isothermal 443 crystallization at a supercooling of $18.7^{\circ} \mathrm{C}$ and Figure $5 \mathrm{C}$ represents the mass fractions of the different 444 polymorphic forms that occurred as a function of the isothermal time. Almost immediately after 445 cooling typical $\alpha$ peaks appeared in both the SAXS and WAXD patterns. After 10 min 5 other peaks 446 started to occur in the WAXD patterns at $2 \theta=9.57^{\circ}(\mathrm{d}=6.23 \AA), 2 \theta=9.80^{\circ}(\mathrm{d}=6.06 \AA), 2 \theta=10.2^{\circ}$ $447(\mathrm{~d}=5.81 \AA), 2 \theta=12.3^{\circ}(\mathrm{d}=4.81 \AA)$ and $2 \theta=12.9^{\circ}(\mathrm{d}=4.61 \AA)$. These spacings coincided with those 448 of the structured form named $\mathrm{PE}_{\mathrm{x}}$ as reported by Daels et al. $(2017)^{14}$. Compared to the WAXD 449 patterns, the $\mathrm{PE}_{\mathrm{x}}$ peaks in the SAXS patterns at $2 \theta=1.07^{\circ}(\mathrm{d}=55.5 \AA)$ (first order) and $2 \theta=2.14^{\circ}(\mathrm{d}=$ $450 \quad 46.7 \AA$ ) (second order) were broader and had a much smaller intensity and therefore could only be 451 clearly distinguished from about 16 min. Since in the SAXS and WAXD patterns of PO with $40 \%$ PEs 452 only peaks with the same spacings as the pure PO and the pure PEs occurred, it can be concluded that 453 the PEs and PO crystallized separately from each other and that no new (compound) crystal structures 454 were formed in this blend. Of the two ordered PE structures described by Daels et al. (2017) ${ }^{14}$ the PE 455 structure was thus formed during isothermal crystallization of PO with $40 \%$ PEs at $18.7^{\circ} \mathrm{C}$ 456 supercooling, which corresponds to a temperature of $16.3^{\circ} \mathrm{C}$. This could be expected from the 457 morphology map of heating reported by Daels et al. (2017) because $16.3^{\circ} \mathrm{C}$ is higher than the melting 458 temperature of $\mathrm{PE}_{\mathrm{y}}$ and lower than the melting temperature of $\mathrm{PE}_{\mathrm{x}}$ in the $40 \% \mathrm{PE}$ blend. Furthermore it 459 was confirmed that the extra peak between Peak I and Peak II in the DSC curve of PO with $40 \%$ PEs 460 was correctly assigned to the crystallization of the PEs (see section 4.2.1.) since the polymorphic 461 transition of $\alpha$ to $\beta^{\prime}$ only started after PE crystallization had begun, more specifically at 19 min. 462 However the XRD data show that the PE crystallization was not completely finished before the $\alpha$ to $\beta$, 
463

464 465

conversion started, which demonstrates that these crystallization events were actually not well separated in time in the DSC crystallization curve. Just as for pure PO and PO with $20 \%$ PE, an isosbestic point appeared in the SAXS patterns during the polymorphic transition from 20 to $45 \mathrm{~min}$ after which extra $\beta$ ' crystals were formed from the liquid phase. The occurrence of an isosbestic point in this time window indicates that the $\mathrm{PE}_{\mathrm{x}}$ crystals do not contribute to any scattering in that angular range but that otherwise - just like for pure PO - all $\beta$ ' crystals are generated from existing $\alpha$ crystals in the initial stage. At the end of the isothermal crystallization the blend consisted of $3 \% \mathrm{PE}_{\mathrm{x}}$ and $7.5 \% \beta^{\prime}$ crystals.

When the results of the XRD analyses are compared with those of the DSC experiments, very similar trends are observed. Both DSC and XRD results showed that the start of the $\alpha$ crystallization occurred immediately after cooling and was almost not delayed as a function of the PE concentration.

However the decreasing trend in the amount of $\alpha$ crystallization upon PE addition was in the WAXD data only visible when more than $20 \%$ PEs was added to PO while $\Delta H_{\alpha}$ of PO (obtained by DSC) already decreased significantly from $20 \%$ PEs addition. This difference is probably due to an incomplete crystallization of the samples at the end of the observed crystallization time as shown by the XRD data which resulted in an uncertain definition of the DSC integration baseline.

Concerning $\beta^{\prime}$ crystallization $t_{\text {ind }}$ as measured by DSC almost equaled the start of the polymorphic transition as observed in SAXS and WAXD, except for the blend with $40 \%$ PEs where $t_{\text {ind }}$ was higher than expected based on the WAXD data. Also a decreasing trend was observed in the amount of $\beta$, crystals formed as measured by DSC ( $a$ value of the Foubert model) as well as by XRD, although for the blend with $40 \%$ PEs the effect was larger when measured by DSC. These deviations between the DSC and the XRD data for the blend with $40 \%$ PE may both be caused by the fact that according to the XRD data the PE crystallization and the $\alpha$ to $\beta^{\prime}$ conversion were not well separated in time in the DSC crystallization curve and by the uncertain definition of the DSC integration baseline as explained before.

\subsection{Polarized light microscopy}


489

490

491

492

493

494

495

496

497

498

499

500

501

502

503

504

505

506

507

508

509

510

511

512

513

514

Figure 7 shows the PLM images of the lipid crystal networks of pure PO and PO with $40 \%$ PEs during isothermal crystallization at a supercooling of $18.7^{\circ} \mathrm{C}$ after an isothermal time of $5 \mathrm{~min}$. According to the DSC and XRD results both samples only contained $\alpha$ crystals of PO at that moment. As can be seen in Figure 7A the typical network of spherulites was seen for $\mathrm{PO}^{26}$. The same type of spherulites were also present in the microstructure of the blend with $40 \%$ PEs but they were much smaller and also the amount was much smaller. In the blends with 10 to $30 \%$ PEs an intermediate microstructure was observed (results not shown). In the microstructure of pure PO the network of $\alpha$ crystals was much denser and more continuous than the microstructure of the blend with $40 \%$ PEs which only showed a weak crystal network, but physically isolated $\alpha$ crystals that were positioned far from each other. The increasing lack of a dense crystal network probably delays the solid-state polymorphic transition of $\alpha$ to $\beta^{\prime}$ upon an increasing PE addition.

\section{Conclusion}

After correcting the isothermal temperature of the PE-PO blends for the difference in the degree of supercooling the increasing effect of PE addition on $t_{\alpha}$ had almost completely disappeared compared to the experiments without correction for the difference in the degree of supercooling. The major effect that remained after correcting the isothermal temperature of the PE-PO blends for the difference in the degree of supercooling is the delay of polymorphic transition (increase in $t_{\text {ind }}$ and $t_{\text {transition }}$ ). This solid-solid transformation needs to be nucleated as well and when not well connected, each $\alpha$ crystal aggregate needs to nucleate on its own, which delays the global transformation process. When well connected, the transformation can travel through the network without the need for frequent primary nucleation of the solid-solid transformation. As indicated by the PLM images the $\alpha$ crystals were physically more isolated from each other at increasing PE concentrations.

Furthermore it was seen that upon an increasing PE concentration less $\beta$ ' crystals were formed, even after correction for the difference in the degree of supercooling of the blends, although it should be noted that the crystallization of the samples was not fully completed at the end of the observed crystallization time. Of course upon PE addition the amount of PO (forming the $\beta$ ' crystals) that was 
515 present in the blend decreased. Furthermore at low PE concentrations the PEs themselves did not 516 crystallize but acted as a liquid oil, diluting the PO.

517 From a practical point of view, avoiding the strong delaying effects on the crystallization rate of PE-PO 518 blends could thus be obtained by lowering the crystallization temperature in order to compensate for 519 the degree of supercooling. However the delay of polymorphic transition of $\alpha$ to $\beta$, which also 520 increases the necessary crystallization time still remains an issue in that case. However, at larger 521 supercooling, the $\alpha$ crystalline content might have increased to the extent that again a percolating 522 network is formed, which should enhance the solid-solid transformation kinetics. Further research is 523 needed to confirm this hypothesis.

\section{6. Abbreviations}

$525 \quad$ maximal amount of crystallization

$526 \Delta H_{\alpha} \quad$ melting enthalpy of the $\alpha$ polymorph

$527 \Delta H_{\text {tot }} \quad$ total melting enthalpy after the isothermal crystallization

528 DSC differential scanning calorimetry

$529 \quad K \quad$ crystallization rate constant

$530 \quad \mathrm{PE}(\mathrm{s}) \quad$ phytosterol ester(s)

531 PLM polarized light microscopy

532 PO palm oil

533 SAXS small angle X-ray scattering

$534 \mathrm{t}_{\alpha \text { peak }} \quad$ peak maximum of the $\alpha$ peak

535 TAG triglyceride

$536 t_{\text {ind }} \quad$ time needed to reach $1 \%$ of the $a$ value

$537 \mathrm{~T}_{\text {offset }} \quad$ offset temperature of melting

$538 t_{\text {transition }}$ polymorphic transition time from $\alpha$ to $\beta$,

539 WAXD wide angle X-ray diffraction

540 XRD X-ray diffraction

\section{7. Acknowledgements}


542 The authors thank FWO Vlaanderen for supporting the DUBBLE project via its Big Science Program.

543 Annelien Rigolle is acknowledged for her assistance with the DSC analyses.

\section{8. Funding sources}

545 This research did not receive any other specific grant from funding agencies in the public, commercial, 546 or non-for-profit sectors. The authors have declared no conflict of interest.

\section{9. References $(\max .50)$}

548 (1) Tan, C. P.; Nehdi, I. A. The Physicochemical Properties of Palm Oil and Its Components. In 549 Palm oil. Production, processing, characterization and uses; Lai, O. M., Tan, C. P., Akoh, C. 550 C., Eds.; AOCS Press: Ur, 2012; pp 377-392.

551

552

553

554

555

556

557

558

559

560

561

562

563

564

(2) Sato, K. Solidification and Phase Transformation Behaviour of Food Fats - a Review. Fett/Lipid 1999, 12, 467-474.

(3) Verstringe, S.; Danthine, S.; Blecker, C.; Depypere, F.; Dewettinck, K. Influence of Monopalmitin on the Isothermal Crystallization Mechanism of Palm Oil. Food Res. Int. 2013, $51(1), 344-353$.

(4) Humphrey, K. L.; Moquin, P. H. L.; Narine, S. S. Phase Behavior of a Binary Lipid Shortening System : From Molecules to Rheology. 2003, 1175-1182.

(5) Chen, C. W.; Lai, O. M.; Ghazali, H. M.; Chong, C. L. Isothermal Crystallization Kinetics of Refined Palm Oil. J. Am. Oil Chem. Soc. 2002, 79 (4), 403-410.

(6) Kawamura, K. The DSC Thermal Analysis of Crystallization Behavior in Palm Oil. J. Am. Oil Chem. Soc. 1979, 56, 753-758.

(7) Ng, W. L.; Oh, C. H. A Kinetic Study on Isothermal Crystallization of Palm Oil by Solid Fat Content Measurement. J. Am. Oil Chem. Soc. 1994, 71 (10), 1135-1139.

(8) Fredrick, E.; Foubert, I.; De Sype, J. Van; Dewettinck, K. Influence of Monoglycerides on the 
(9) Piironen, V.; Lindsay, D. G.; Miettinen, T. A.; Toivo, J.; Lampi, A. Review Plant Sterols :

Biosynthesis, Biological Function and Their Importance to Human Nutrition. J. Sci. Food Agric.

(10) Ras, R. T.; Geleijnse, J. M.; Trautwein, E. A. LDL-Cholesterol-Lowering Effect of Plant Sterols and Stanols across Different Dose Ranges: A Meta-Analysis of Randomised Controlled Studies.

Br. J. Nutr. 2014, 112, 214-219.

572

573

(11) Ntanios, F. Plant Sterol-Ester-Enriched Spreads as an Example of a New Functional Food. Eur. J. Clin. Nutr. 2001, 103, 102-106.

574

575

576

577

578

579

580 2000, 80, 939-966.

(12) Salo, P.; Wester, I.; Hopia, A. Phytosterols. In Lipids for Functional Foods and Nutraceuticals; Gunstone, F. D., Ed.; The Oily Press: Bridgwater, England, 2003; pp 183-224.

(13) European Commission. Opinion of the Scientific Committee on Food on a Report on Post Launch Monitoring of "yellow Fat Spreads with Added Phytosterol Esters; 2002.

(14) Daels, E.; Foubert, I.; Goderis, B. The Effect of Adding a Commercial Phytosterol Ester Mixture on the Phase Behavior of Palm Oil. Food Res. Int. 2017, 100, 841-849.

(15) Daels, E.; Goderis, B.; Foubert, I. Influence of the Addition of a Commercial Phytosterol Ester Mixture on the "Equilibrium " Crystallization Behavior of Palm Oil. (unpublished data) 2018.

(16) Smith, K. W.; Bhaggan, K.; Talbot, G.; Malssen, K. F. Crystallization of Fats: Influence of Minor Components and Additives. J. Am. Oil Chem. Soc. 2011, 88 (8), 1085-1101.

(17) Panpipat, W.; Xu, X.; Guo, Z. Improved Acylation of Phytosterols Catalyzed by Candida Antarctica Lipase A with Superior Catalytic Activity. Biochem. Eng. J. 2013, 70, 55-62.

(18) Ryckebosch, E.; Bruneel, C.; Termote-Verhalle, R.; Goiris, K.; Muylaert, K.; Foubert, I. 
587

588

589

590

591

592

593

594

595

596

597

598

599

600

601

602

603

604

605

606

607

608

Nutritional Evaluation of Microalgae Oils Rich in Omega-3 Long Chain Polyunsaturated Fatty Acids as an Alternative for Fish Oil. Food Chem. 2012, 160, 393-400.

(19) Ryckebosch, E.; Muylaert, K.; Foubert, I. Optimization of an Analytical Procedure for Extraction of Lipids from Microalgae. J. Am. Oil Chem. Soc. 2012, 89, 189-198.

(20) Foubert, I.; Vanrolleghem, P. A.; Dewettinck, K. A Differential Scanning Calorimetry Method to Determine the Isothermal Crystallization Kinetics of Cocoa Butter. 2002, 400 (2003), 131142.

(21) Foubert, I.; Fredrick, E.; Vereecken, J.; Sichien, M.; Dewettinck, K. Stop-and-Return DSC Method to Study Fat Crystallization. Thermochim. Acta 2008, 471, 7-13.

(22) Timms, R. E. Confectionery Fats Handbook. Oily Press 2003, p 454.

(23) Gommes, C. J.; Goderis, B. CONEX, a Program for Angular Calibration and Averaging of TwoDimensional Powder Scattering Patterns. J. Appl. Crystallogr. 2010, 43 (2), 352-355.

(24) Foubert, I.; Vanrolleghem, P. a; Vanhoutte, B.; Dewettinck, K. Dynamic Mathematical Model of the Crystallization Kinetics of Fats. Food Res. Int. 2002, 35 (10), 945-956.

(25) Foubert, I.; Dewettinck, K.; Van de Walle, D.; Dijkstra, A. J.; Quinn, P. J. Physical Properties: Structural and Physical Characteristics. In The Lipid Handbook; Gunstone, F. D., Harwood, J. L., Dijkstra, A. J., Eds.; CRC Press: Boca Raton, 2007; pp 471-534.

(26) Peyronel, F.; Marangoni, A. G. In Search of Confectionary Fat Blends Stable to Heat: Hydrogenated Palm Kernel Oil Stearin with Sorbitan Monostearate. Food Res. Int. 2014, 55, 93102. 


\section{10. Tables}

610 Table 1. Sterol composition (\%) of the commercial phytosterol ester mixture. The values show the 611 average of two measurements. The error is $0.2 \%$.

612

\begin{tabular}{lr}
\hline Sterol & \\
\hline Brassicasterol & 1.3 \\
Campesterol & 10.0 \\
Stigmasterol & 0.6 \\
$\beta$-sitosterol & 78.5 \\
$\beta$-sitostanol & 9.7 \\
\hline
\end{tabular}

613 
614 Table 2. Fatty acid composition (\%) of palm oil and the commercial phytosterol ester mixture. The 615 values show the average of three measurements. The error is $0.2 \%$.

\begin{tabular}{lrr}
\hline Fatty acid & Palm oil & $\begin{array}{r}\text { Phytosterol ester } \\
\text { mixture }\end{array}$ \\
\hline C14:0 & 1.0 & - \\
C16:0 & 45.4 & 6.6 \\
C18:0 & 4.3 & 3.8 \\
C18:1 & 39.6 & 29.8 \\
C18:2 & 9.8 & 59.7 \\
\hline
\end{tabular}

616

617 
618 Table 3. Triglyceride (TAG) composition (\%) of palm oil. The values show the average of two 619 measurements. The error is $0.02 \%$. Abbreviations: L: linoleic acid, O: oleic acid, P: palmitic acid, M: 620 myristic acid, S: stearic acid

\begin{tabular}{lr}
\hline TAG & \\
\hline PLL & 2.71 \\
MLP & 0.67 \\
OOL & 1.87 \\
POL & 10.97 \\
PLP & 10.54 \\
OOO & 3.62 \\
POO & 23.14 \\
POP & 31.42 \\
PPP & 5.15 \\
SOO & 2.49 \\
POS & 5.64 \\
PPS & 1.08 \\
SOS & 0.70 \\
\hline
\end{tabular}


Table 4. Peak maximum of crystallization peak I $\left(t_{\alpha}\right)$ for isothermal crystallization, melting enthalpy $\left(\Delta H_{\alpha}\right)$ of the stop-and-return melting profiles, parameters resulting from the Foubert model fit, transition time $\left(t_{\text {transition }}\right)$ and total melting enthalpy after isothermal crystallization $\left(\Delta H_{\text {tot }}\right)$ for the pure PO and the blends containing

\begin{tabular}{|c|c|c|c|c|c|c|c|c|c|c|c|}
\hline$\% \mathrm{PE}$ & $\mathrm{t}_{\alpha}(\min )$ & & $\Delta \mathrm{H}_{\alpha}(\mathrm{J} / \mathrm{g})$ & & $a(\mathrm{~J} / \mathrm{g})$ & & $t_{\text {ind }}(\min )$ & $\mathrm{K}(1 / \mathrm{s})$ & & $t_{\text {transition }}(\min )$ & $\Delta \mathrm{H}_{\mathrm{tot}}(\mathrm{J} / \mathrm{g})$ \\
\hline 0 & $0.7 \pm 0.1$ & $\mathrm{a}$ & $6.1 \pm 0.2$ & $\mathrm{a}$ & $9.4 \pm 0.4$ & $\mathrm{a}$ & $8.5 \pm 0.2^{a}$ & $10.9 \pm 0.5$ & $\mathrm{a}$ & $7.8 \pm 0.2^{a}$ & $15.5 \pm 0.6$ \\
\hline 10 & $1.1 \pm 0.2$ & a & $4.7 \pm 0.1$ & $\mathrm{~b}$ & $8.0 \pm 0.0$ & $\mathrm{~b}$ & $10.0 \pm 0.2^{b}$ & $9.3 \pm 0.9$ & $\mathrm{~b}$ & $8.9 \pm 0.3^{a}$ & $12.6 \pm 0.2$ \\
\hline 20 & $2.4 \pm 0.7$ & $\mathrm{~b}$ & $2.8 \pm 0.2$ & $\mathrm{c}$ & $5.7 \pm 0.3$ & $\mathrm{c}$ & $12.6 \pm 1.1^{\mathrm{c}}$ & $5.3 \pm 0.4$ & c & $10.2 \pm 1.3^{b}$ & $8.5 \pm 0.5$ \\
\hline 30 & $7.7 \pm 0.6$ & c & $1.8 \pm 0.1$ & d & $4.5 \pm 0.2$ & d & $22.4 \pm 0.7^{\mathrm{d}}$ & $3.1 \pm 0.2$ & d & $14.7 \pm 1.0^{\mathrm{c}}$ & $6.4 \pm 0.2$ \\
\hline 40 & $17.1 \pm 0.9$ & d & $0.6 \pm 0.1$ & e & $7.1 \pm 0.3$ & e & $35.8 \pm 1.2^{\mathrm{e}}$ & $3.5 \pm 0.0$ & d & $18.7 \pm 1.5 \mathrm{~d}$ & $7.7 \pm 0.3$ \\
\hline
\end{tabular}


629 Table 5. $\mathrm{T}_{\text {offset }}$ of the pure PO and the blends containing 10\%, 20\%, 30\% and 40\% phytosterol esters (PEs) and 630 the calculated isothermal temperature based on the average $\mathrm{T}_{\text {offset }}$ inducing a degree of supercooling of $18.7^{\circ} \mathrm{C}$ for 631 all the blends. $\mathrm{T}_{\text {offset }}$ shows the average \pm standard deviation $(\mathrm{n}=5)$.

\begin{tabular}{lccc}
\hline$\%$ PEs & $\mathrm{T}_{\text {offset }}\left({ }^{\circ} \mathrm{C}\right)$ & Isothermal temperature $\left({ }^{\circ} \mathrm{C}\right)$ \\
\hline 0 & 38.7 & $\pm 0.2^{\mathrm{a}}$ & 20.0 \\
10 & 38.0 & $\pm 0.3^{\mathrm{b}}$ & 19.3 \\
20 & 36.7 & $\pm 0.2^{\mathrm{c}}$ & 18.1 \\
30 & 35.9 & $\pm 0.2^{\mathrm{d}}$ & 17.3 \\
40 & 35.0 & $\pm 0.4^{\mathrm{e}}$ & 16.3 \\
\hline
\end{tabular}

632

633 
Table 6. Peak maximum of crystallization peak I $\left(t_{\alpha}\right)$ for isothermal crystallization, melting enthalpy $\left(\Delta H_{\alpha}\right)$ of the stop-and-return melting profiles, Parameters resulting from the Foubert model fit, transition time $\left(t_{\text {transition }}\right)$ and total melting enthalpy after isothermal crystallization $\left(\Delta H_{\text {tot }}\right)$ for the pure PO and the blends

\begin{tabular}{|c|c|c|c|c|c|c|c|c|c|}
\hline$\% \mathrm{PE}$ & $t_{\alpha}(\min )$ & & $\Delta \mathrm{H}_{\alpha}(\mathrm{J} / \mathrm{g})$ & $a(\mathrm{~J} / \mathrm{g})$ & $\mathrm{t}_{\text {ind }}(\min )$ & $\mathrm{K}(1 / \mathrm{s})$ & & $t_{\text {transition }}(\min )$ & $\Delta \mathrm{H}_{\mathrm{tot}}(\mathrm{J} / \mathrm{g})$ \\
\hline 0 & $0.7 \pm 0.1$ & $\mathrm{a}$ & $6.1 \pm 0.2^{a}$ & $9.4 \pm 0.4$ & $8.5 \pm 0.2$ & $10.9 \pm 0.5$ & $\mathrm{a}$ & $7.8 \pm 0.2^{a}$ & $15.5 \pm 0.6^{\mathrm{a}}$ \\
\hline 10 & $0.7 \pm 0.1$ & a & $5.4 \pm 2.2^{\mathrm{a}, \mathrm{b}}$ & $7.9 \pm 0.3$ & $10.5 \pm 0.6$ & $12.1 \pm 1.5$ & a & $9.8 \pm 0.6 \quad$ b & $13.3 \pm 2.2^{\mathrm{a}, \mathrm{b}}$ \\
\hline 20 & $0.7 \pm 0.1$ & a & $3.4 \pm 0.5^{b}$ & $7.6 \pm 0.5$ & $11.7 \pm 0.5$ & $8.8 \pm 0.8$ & $\mathrm{~b}$ & $11.1 \pm 0.5^{\mathrm{c}}$ & $11.1 \pm 0.3^{b}$ \\
\hline 30 & $0.8 \pm 0.1$ & $\mathrm{a}, \mathrm{b}$ & $3.5 \pm 0.3^{b}$ & $7.8 \pm 0.4$ & $15.0 \pm 0.8$ & $7.2 \pm 0.8$ & c & $14.2 \pm 0.8^{\mathrm{d}}$ & $11.3 \pm 0.6^{b}$ \\
\hline 40 & $0.8 \pm 0.1$ & $\mathrm{~b}$ & - & $4.1 \pm 0.1$ & $23.8 \pm 0.4$ & $7.1 \pm 0.4$ & $\mathrm{c}$ & $23 \pm 0.4^{\mathrm{e}}$ & - \\
\hline
\end{tabular}


637 Figure 1. Illustration of the method to make the cleaned reference patterns of the different polymorphic 638 forms, being $\alpha(\mathrm{A}), \beta^{\prime}(\mathrm{B})$ and $\mathrm{PE}_{\mathrm{x}}$, of which a linear combination was used to fit the WAXD patterns 639 of selected samples in order to quantitatively analyze the fractions of the different polymorphic forms 640 as a function of the isothermal time.

641 Figure 2. Overlay plot of isothermal DSC crystallization curves of the pure palm oil and the pure 642 phytosterol esters (PEs) and the blends containing 10\%, 20\%, 30\% and 40\% PEs at $20^{\circ} \mathrm{C}$ (Exo up) (A) 643 and the same plot but zoomed in on Peak I (B). Peak maxima of Peak I ( $\alpha$ crystallization) and Peak II 644 ( $\beta^{\prime}$ crystallization) are indicated with different symbols above the peak: Peak I (•) and Peak II (०).

645 Figure 3. Overlay plot of isothermal DSC crystallization curves of the pure palm oil and the blends 646 containing 10\%,20\%,30\% and 40\% phytosterol esters (PE) at a constant degree of supercooling of $64718.7^{\circ} \mathrm{C}$ (Exo up) (A) and an overlay plot of the same curves, zoomed in on Peak I ( $\alpha$ crystallization) 648 (B). Peak maxima of Peak II ( $\beta^{\prime}$ crystallization) are indicated with a symbol (०) above the peak.

649 Figure 4. SAXS and WAXD diffraction patterns at different times during the isothermal crystallization 650 of pure palm oil at $20^{\circ} \mathrm{C}$.

651 Figure 5. Mass fraction of the different polymorphs as measured by WAXD during isothermal 652 crystallization at a constant degree of supercooling of $18.7^{\circ} \mathrm{C}$. A: pure palm oil (PO), B: PO with $20 \%$ 653 phytosterol esters (PEs), C: PO with 40\% PEs.

Figure 6. SAXS and WAXD diffraction patterns at different times during the isothermal crystallization 655 of palm oil with $40 \%$ PEs at $16.3^{\circ} \mathrm{C}$.

656 Figure 7. Polarized light microscopy images of the lipid crystal networks of pure palm oil (A) and 657 palm oil with $10 \%, 20 \%, 30 \%$ and $40 \%$ PEs (B) during isothermal crystallization at a degree of 658 supercooling of $18.7^{\circ} \mathrm{C}$ after an isothermal time of $5 \mathrm{~min}$. 
Isothermal crystallization of palm oil with addition of phytosterol esters (PE)

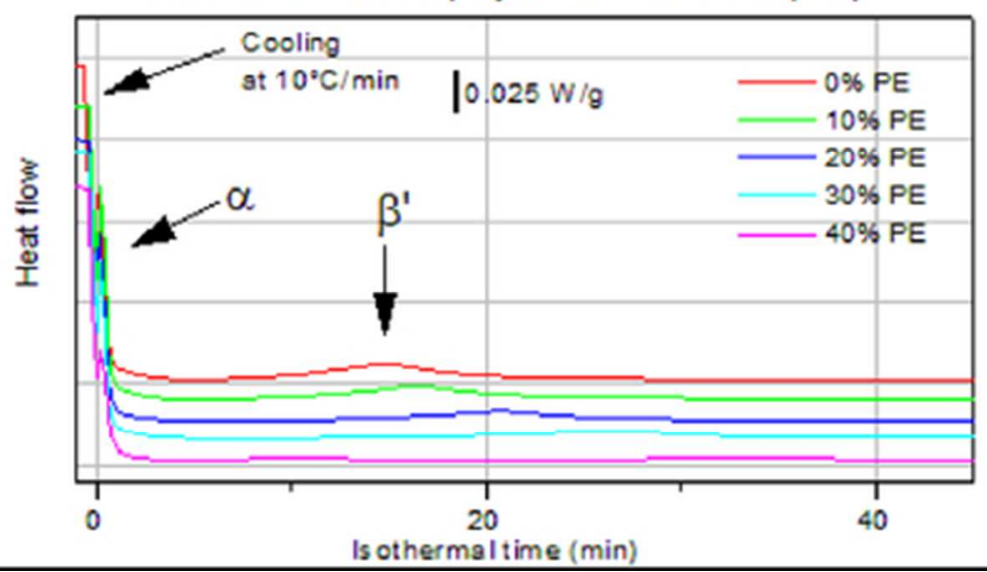

TOC Graphic

$44 \times 23 \mathrm{~mm}(300 \times 300 \mathrm{DPI})$ 


A

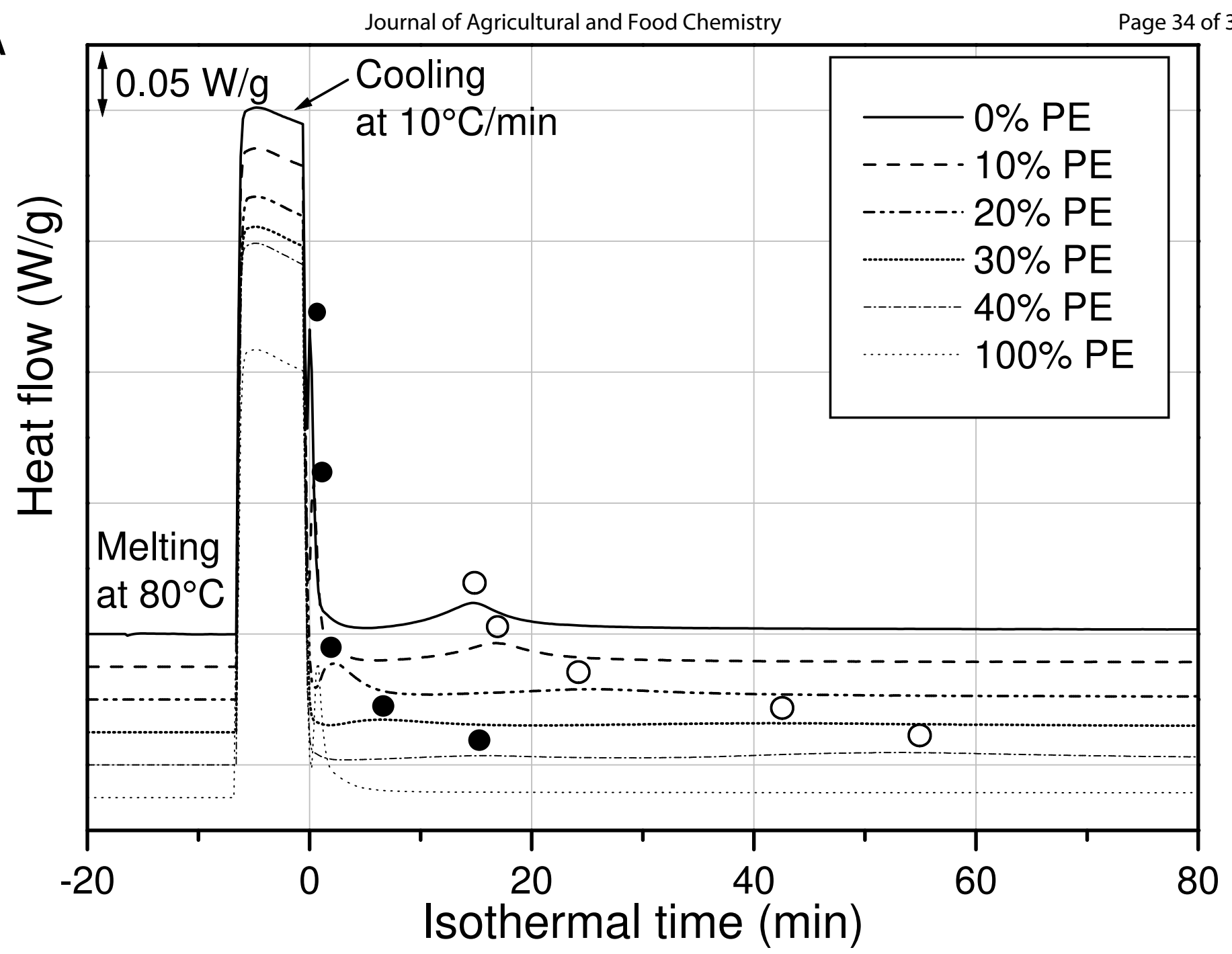

B

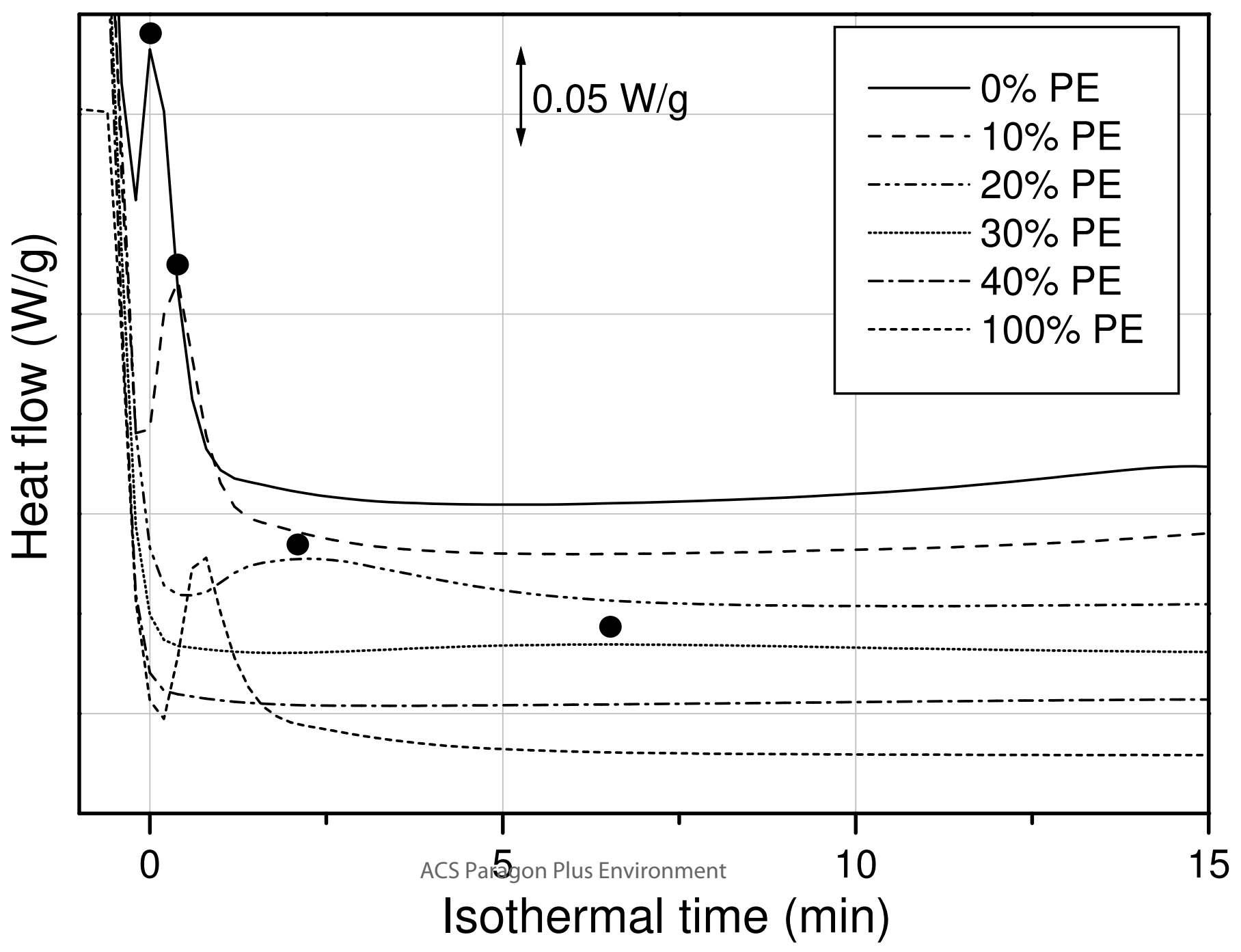


A

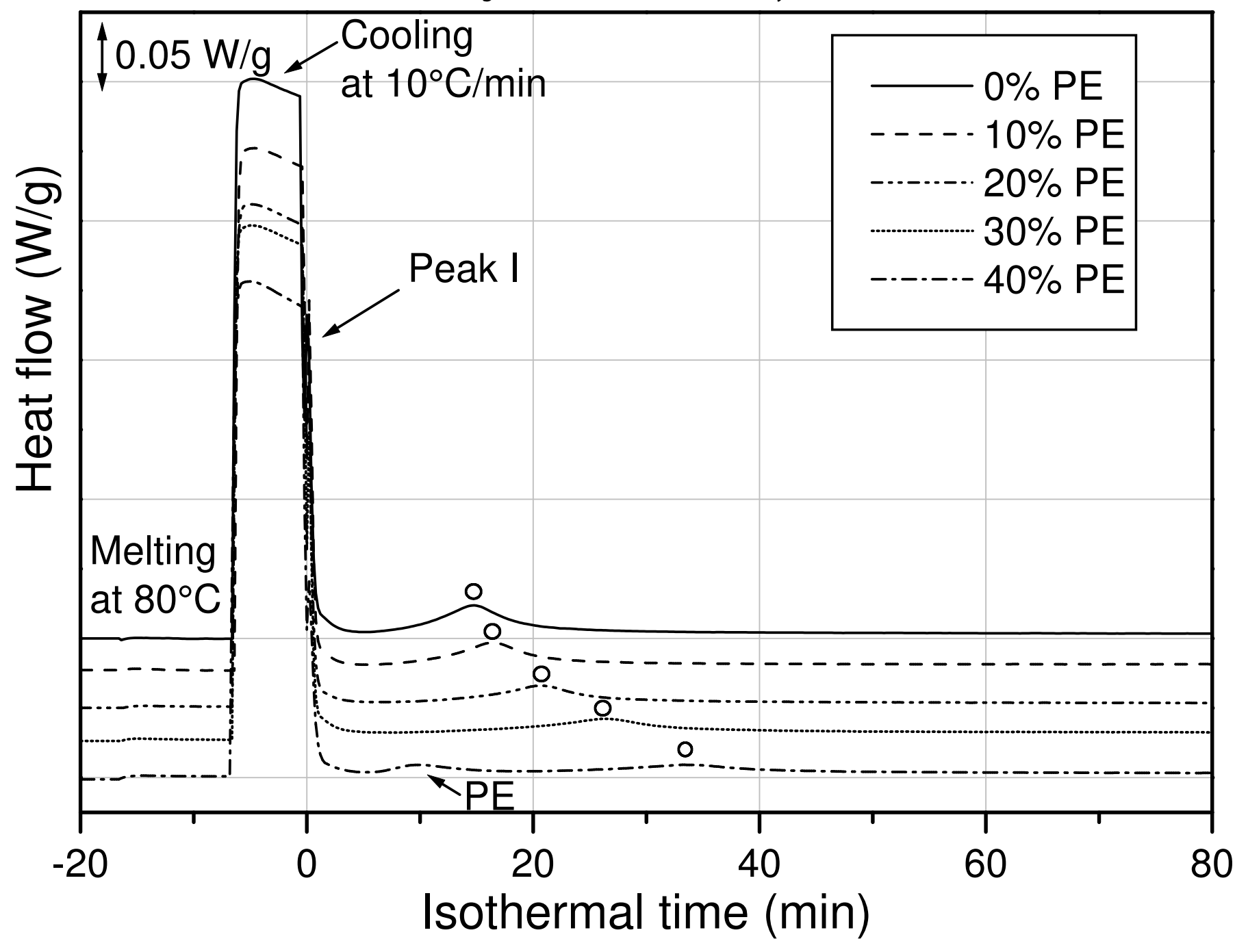

B

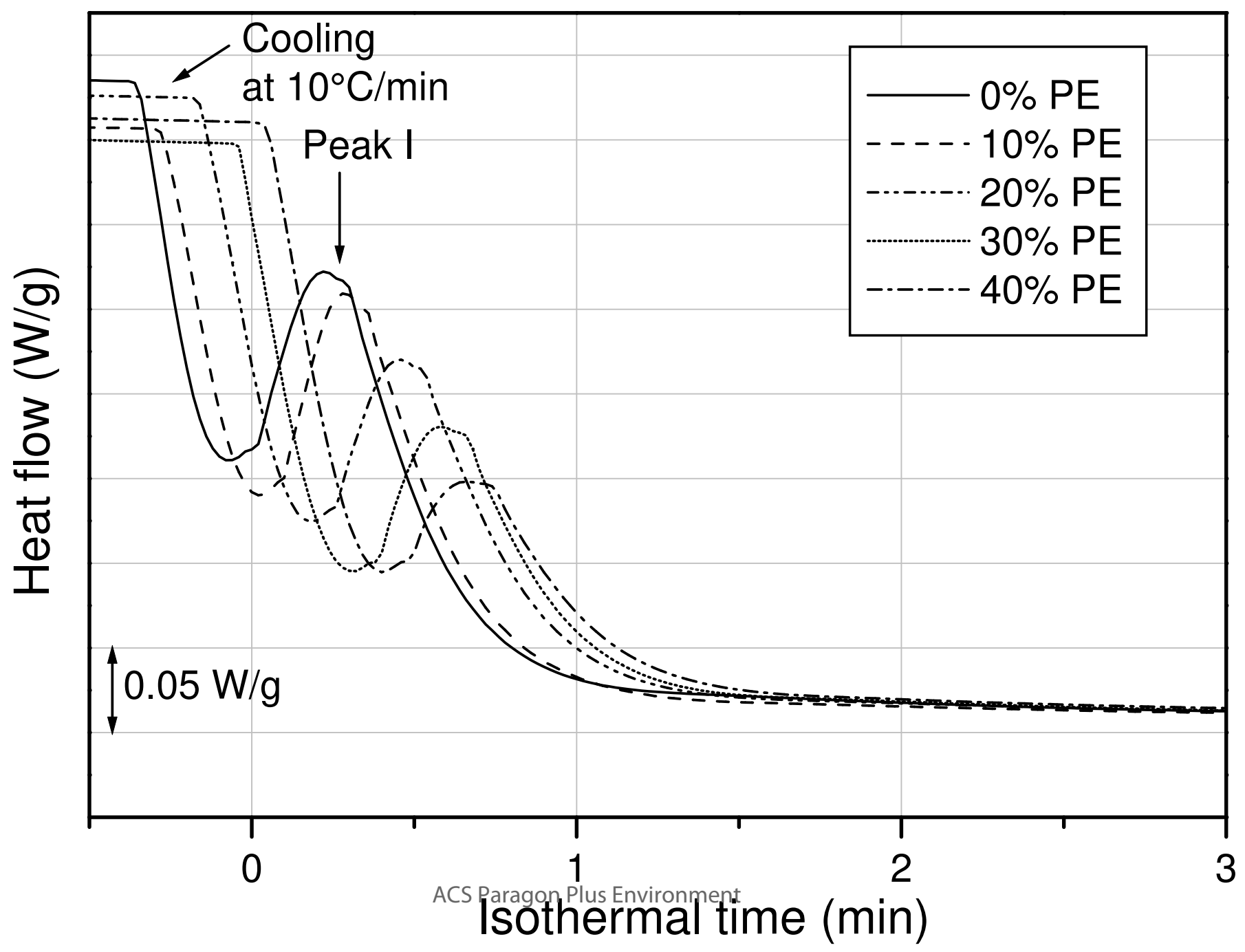


SAX Sournal of Agricultural and food chemistry $\quad$ WAXD Page 36 of 39


Scattering angle $\left({ }^{\circ} 2 \theta, \lambda=1.033 \AA\right.$ )
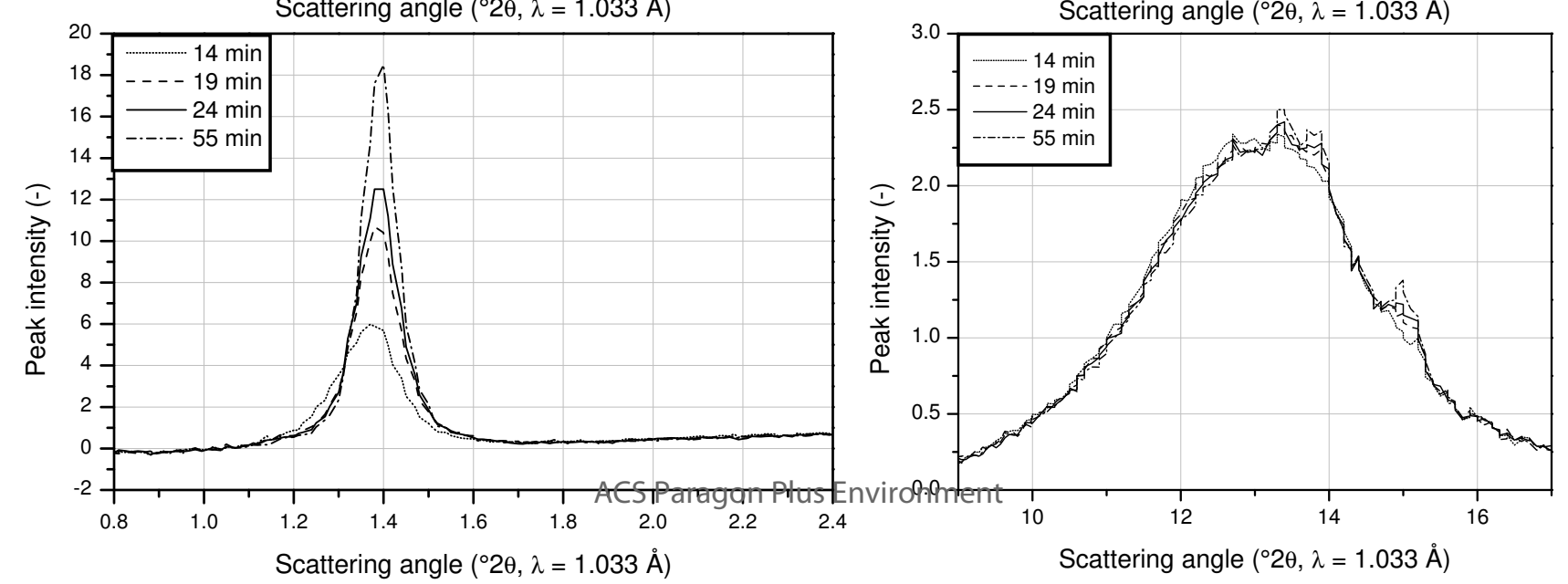
SAXS Journal of Agricultural and Food Chemistry WAXD
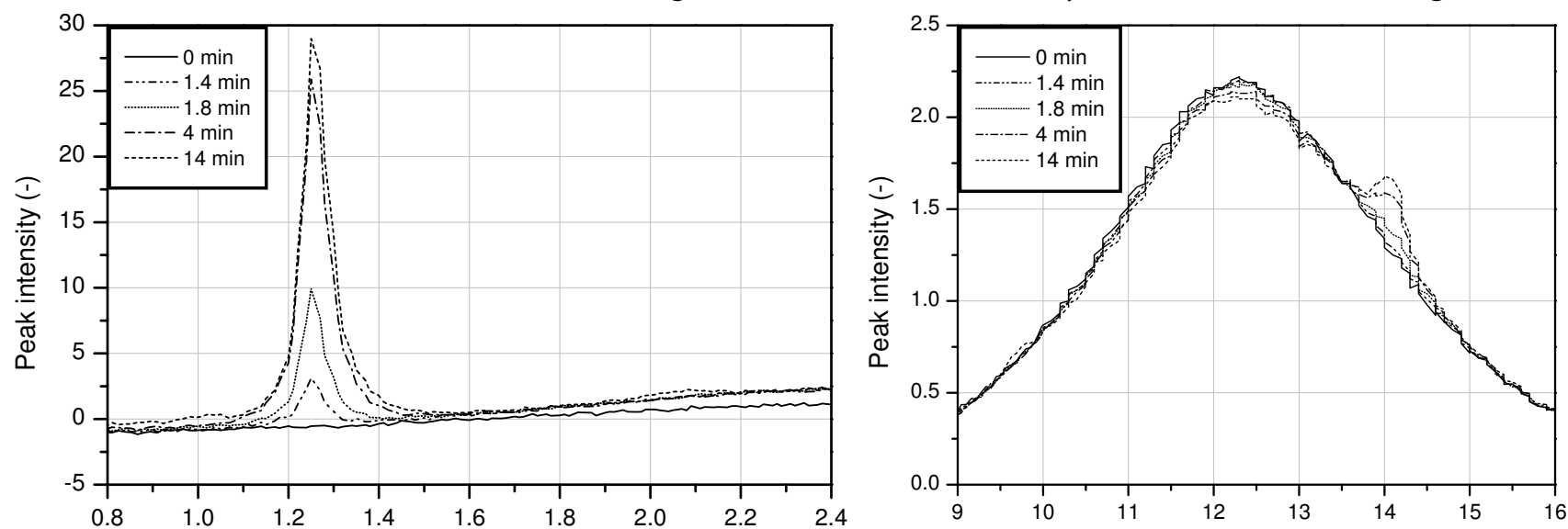

Scattering angle $\left({ }^{\circ} 2 \theta, \lambda=1.033 \AA\right)$
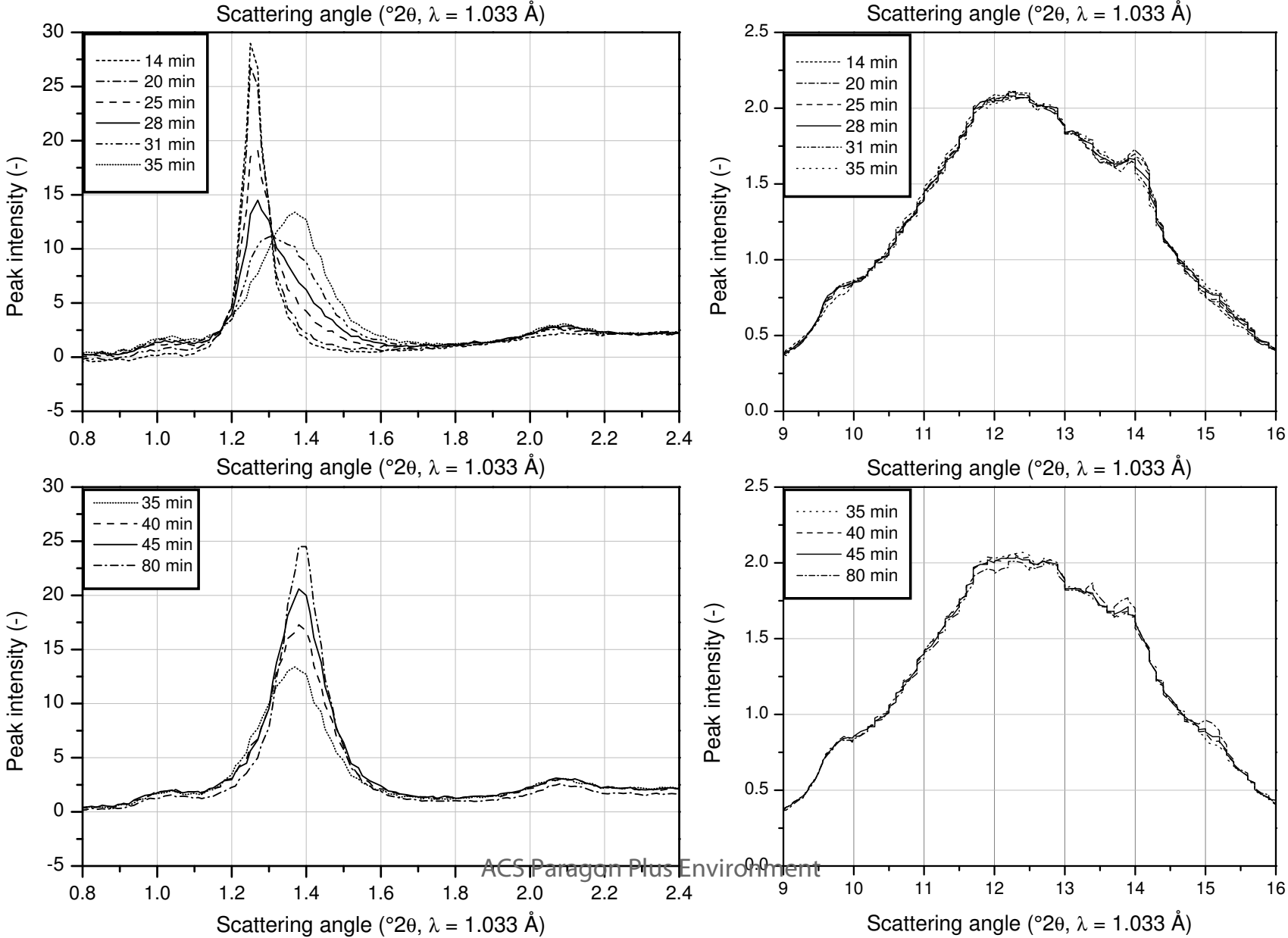
roy



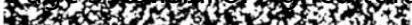

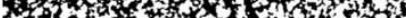

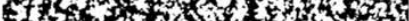

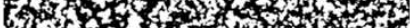



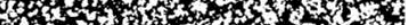



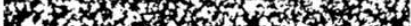



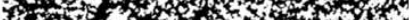

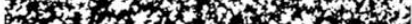

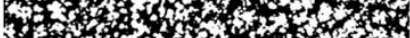

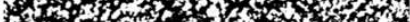

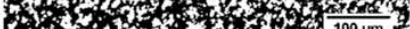

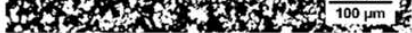

\section{$0 \%$ PES}

W10 $20 \%$ PES

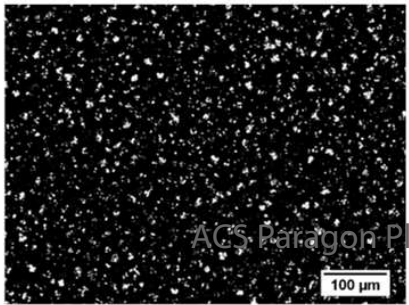

$40 \%$ PES

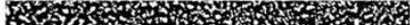
6.0. S.



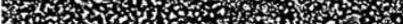

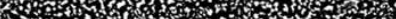

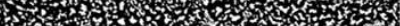

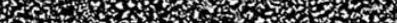

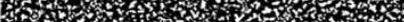

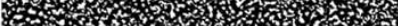

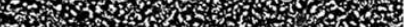



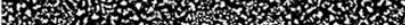

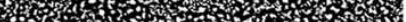

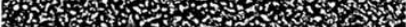





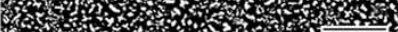
40 s.

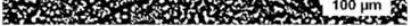

\section{$10 \%$ PES}

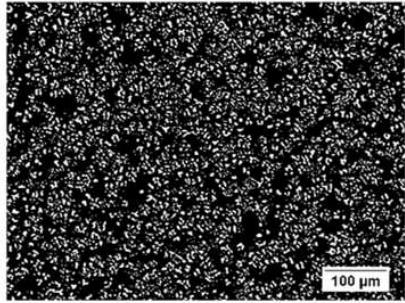

$30 \%$ PES 